joint space width. Consequently, periarticular demineralisation and finger joint space narrowing presented two different and independent radiological signs in PsA.

References: N/A

Disclosure of Interests: Alexander Pfeil Grant/research support from: This study Investigator Initiated Study "Automatic assessment of joint space narrowing in rheumatoid arthritis based on the Post-hoc analysis" (number: IIS-2016-110818) is a part of the of the Investigator Initiated Study "The quantification of inflammatory related periarticular bone loss in certolizumab pegol treated patients with rheumatoid arthritis" (number: IIS-2014-101458) which is supported by UCB Pharma GmbH, Monheim, Germany., Marcus Heinz: None declared, Diane Renz: None declared, Joachim Böttcher: None declared, Gunter Wolf: None declared, Peter Oelzner: None declared

DOI: 10.1136/annrheumdis-2020-eular.3703

\section{AB0823 MINIMAL DISEASE ACTIVITY IN PSORIATIC ARTHRITIS IS ASSOCIATED WITH LOW IMPACT OF DISEASE ON PSAID12 QUESTIONAIRE}

J. A. Mosquera Martínez¹, C. García-Porrúa², L. Fernández-Dominguez³ , J. L. Guerra-Vazquez ${ }^{4}$, J. Pinto-Tasende ${ }^{5}$ on behalf of GIGAPS. ${ }^{1} \mathrm{CHU}$ Pontevedra, Rheumatology, Pontevedra, Spain; ${ }^{2}$ Hospital Lucus Augusti, Rheumatology, Lugo, Spain; ${ }^{3} \mathrm{CHU}$ Ourense, Rheumatology, Ourense, Spain; ${ }^{4} \mathrm{CHU}$ Arquitecto Marcide, Rheumatology, Ferrol, Spain; ${ }^{5}$ INIBIC-CHU A Coruña, Rheumatology, A Coruña, Spain

Background: Psoriatic arthritis (PsA) has a prevalence of $0.58 \%$ in Spain and patients suffer this disease have significant impact on daily life due to articular, dermatological and psychological symptoms. To reach minimal disease activity (MDA) is a therapeutic goal recommended by EULAR for clinical practice.

Objectives: Our aim was to assess the relationship between MDA and PSAID questionnaire in routine clinical practice.

Methods: We performed a cross-sectional study of patient and physician reported outcomes. We obtained clinical information of patients with PsA attending clinic from October 2018 to October 2019. Data were collected from clinical records concerning age, gender, disease duration, joint counts, dactylitis, enthesitis, body surface area (BSA) of psoriasis, laboratory results (ESR and CRP), HAQ, PsAID12, pain and global assessment from patient with numerical rating scale (NRS) and MDA status. Data were analysed using SPSS21. Logistic regression was used to assess patient reported outcomes which were associated with achieving MDA

Results: Data were available for 210 patient visits, 57\% males. MDA 5/7 was reached in 118 patients (56.2\%) and MDA7/7 in 58 (27.6\%). Age and gender were not associated with reach MDA. Higher disease duration was associated with MDA, OR $1.062(1.012-1.114,95 \% \mathrm{Cl}), \mathrm{p} 0.015$

PsAID12 was evaluated in 156 patients and all components were associated with reach MDA. Patients in MDA had significantly lower PsAID12 than those were not in MDA (mean $1.5 \pm$ SD 1.5 vs. $3.8 \pm 2.1$ ),$p<0.0001$. PSAID12 of less than 4 is considered a good outcome and individual components of PSAID12 (Figure 1, mean values for NRS) were less than 4 in patients with MDA.

\section{PsAID12}

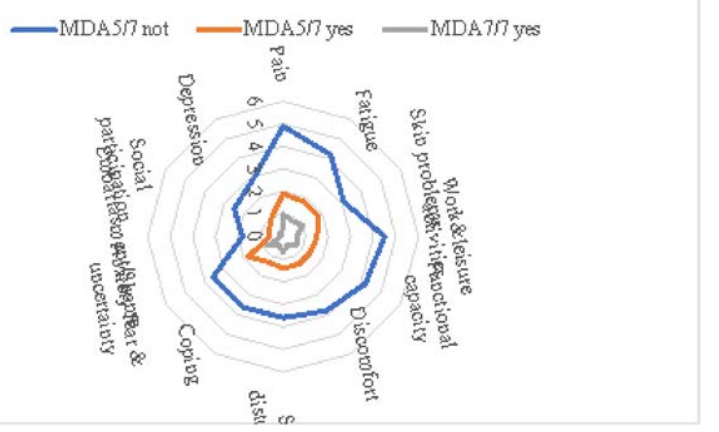

Figure 1.
All components of PSAID12 were associated with MDA on univariate analysis but only pain and functional capacity remained independent predictors on multiple regression analysis ( $p<0.0001$ and $\mathrm{p} 0.008$ respectively).

Percentage of BSA was associated with skin component of PSAID12 $(p<0.0001)$ and with shame component (p0.001).

Conclusion: In these PsA patients, MDA was reached mainly in patients with higher disease duration. MDA is a relevant treatment target in PsA, with markedly lower PsAID12 in patients in MDA. Pain and functional discapacity are dominant symptoms in patients with psoriatic arthritis, even in those in MDA. Skin affection is associated with skin and shame components on the PsAID12.

References:

[1] Queiro R et al. Arthritis Res Ther. 2017 Mar 29;19(1):72.

Acknowledgments: SOGARE

Disclosure of Interests: José Antonio Mosquera Martínez: None declared, Carlos García-Porrúa: None declared, Luis Fernández-Dominguez: None declared Jose L. Guerra-Vazquez: None declared, Jose Pinto-Tasende Consultant of Janssen, Novartis, Speakers bureau: Lilly, Janssen, Novartis, BMS, Pfizer Celgene

DOI: 10.1136/annrheumdis-2020-eular.4722

\section{AB0824 WHICH PARAMETERS ARE RELEVANT IN THE IDENTIFYING AXIAL INVOLVEMENT IN PSORIATIC ARTHRITIS? - RESULTS OF A SURVEY AMONG ASAS AND GRAPPA MEMBERS}

D. Poddubnyy ${ }^{1}$, P. J. Mease ${ }^{2}$, F. Van den Bosch ${ }^{3}$, J. Braun ${ }^{4}$, A. Gottlieb ${ }^{5}$, L. C. Coates ${ }^{6}$, V. Chandran ${ }^{7}$, P. Helliwell ${ }^{8}$, D. Jadon ${ }^{9}$, J. Sieper ${ }^{1}$, D. Van der Heijde ${ }^{10}$, D. D. Gladman ${ }^{7}$ on behalf of ASAS, GRAPPA. ${ }^{1}$ Charité Universitätsmedizin Berlin, Berlin, Germany; ${ }^{2}$ Swedish Medical Center Providence St. Joseph Health and University of Washington, Seattle, United States of America; ${ }^{3}$ Ghent University, VIB Center for Inflammation Research, Ghent, Belgium; ${ }^{4}$ Rheumazentrum Ruhrgebiet, Ruhr-University Bochum, Herne, Germany; ${ }^{5}$ Icahn School of Medicine at Mount Sinai, New York, United States of America; ${ }^{6}$ University of Oxford, Oxford, United Kingdom; ${ }^{7}$ Toronto Western Hospital, Toronto, Canada; ${ }^{8}$ Leeds Institute of Rheumatology and Musculoskeletal Medicine, University of Leeds, Leeds, United Kingdom; ${ }^{9}$ Cambridge University Hospitals, Cambridge, United Kingdom; ${ }^{10}$ Leiden University Medical Centre, Leiden, Netherlands

Background: Inflammatory involvement of the axial skeleton (sacroiliac joints and / or spine) is one of the relatively frequent musculoskeletal manifestations associated with psoriasis / psoriatic arthritis ( $\mathrm{PsA})$. There is an urgent need for an evidence-based definition for axial involvement in PsA that would identify a subgroup of patients within the heterogeneous PSA population to conduct observational, interventional and translational studies. ASAS and GRAPPA embarked on a collaborative initiative to develop a definition of axial involvement in PsA.

Objectives: To perform a survey to identify variables relevant in the identification of the presence of axial involvement in PsA among members of ASAS and GRAPPA.

Methods: The online survey utilized the PAPRIKA methodology (Potentially $\mathbf{A} /$ Pairwise RanKings of all possible Alternatives) that determines decision-makers' part-worth utilities representing the relative importance of the attributes. Participants were exposed to number of clinical scenarios and were prompted to decide which of the scenarios is more compatible with axial involvement in PsA unless they are equal (Figure). The constant stem of each scenario was "a patient diagnosed with psoriatic arthritis fulfilling the CASPAR criteria"; the variable part included 13 common spondyloarthritis variables (Table). Variables were ranked according to their relative importance.

Results: The survey was completed by 186 ASAS/GRAPPA members (63 ASAS only, 80 GRAPPA only, and 43 both societies). The ranking of the variables is presented in Table. The highest ranked parameters indicative of axia involvement in a patient with PsA were presence of typical radiographic or $\mathrm{MRI}$ changes in the sacroiliac joints and/or spine followed by the presence of chronic back pain and then inflammatory back pain. A separate analysis of ASAS and GRAPPA members provided the similar results concerning the relevance of the variables.

Conclusion: Objective signs of inflammatory involvement of the axial skeleton are the most important indicators of axial disease in PsA in the opinion of the experts. A prospective cohort study is currently being planned to address the value of these and other variables in defining axial involvement in PSA. 
Table. Ranking of the parameters relevant to deciding on the presence of axial involvement in a PsA patient in the opinion of ASAS and GRAPPA members $(n=186)$.

\begin{tabular}{|c|c|c|c|}
\hline $\mathbf{N}$ & Parameters & $\begin{array}{c}\text { Median } \\
\text { rank }\end{array}$ & Mean rank \\
\hline 1 & Presence of structural damage on an X-ray of SIJ & 2 & 2.8 \\
\hline 2 & Presence of structural damage on an X-ray of spine & 3.5 & 4.1 \\
\hline 3 & $\begin{array}{l}\text { Presence of subchondral BME / osteitis on MRI of SIJ } \\
\text { compatible with SpA }\end{array}$ & 4 & 4.5 \\
\hline 4 & $\begin{array}{l}\text { Presence of BME / osteitis on MRI of spine compatible } \\
\text { with SpA }\end{array}$ & 4 & 5 \\
\hline 5 & History or current presence of back pain & 5.5 & 5.8 \\
\hline 6 & History of or current presence of inflammatory back pain & 5.5 & 6 \\
\hline 7 & $\begin{array}{l}\text { Good response of back pain to non-steroidal anti-inflam- } \\
\text { matory drugs }\end{array}$ & 8 & 7.8 \\
\hline 8 & HLA-B27 & 8 & 8.1 \\
\hline 9 & Family history for SpA & 9.5 & 9 \\
\hline 10 & Elevated C-reactive protein & 10 & 9.3 \\
\hline 11 & $\begin{array}{l}\text { Presence of peripheral arthritis and/or enthesitis and/ } \\
\text { or dactylitis }\end{array}$ & 10 & 9.4 \\
\hline 12 & Presence of anterior uveitis & 10 & 9.5 \\
\hline 13 & Presence of inflammatory bowel disease & 10 & 9.6 \\
\hline
\end{tabular}

$\mathrm{BME}=$ bone marrow edema, $\mathrm{MRI}=$ magnetic resonance imaging, $\mathrm{SIJ}=$ sacroiliac joints, $\mathrm{SpA}=$ spondyloarthritis

Figure. An example of a survey question with two clinical scenarios comparing two pairs of parameters to determine part-worth utilities of the parameters.

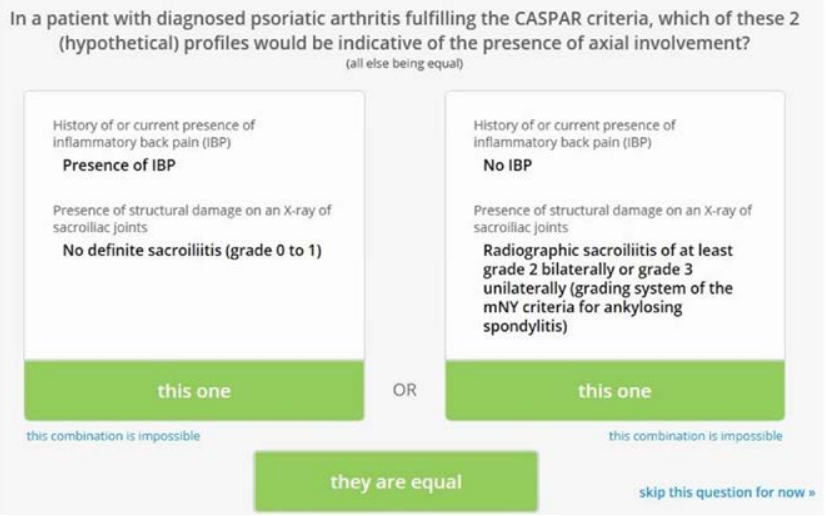

Disclosure of Interests: Denis Poddubnyy Grant/research support from: AbbVie, MSD, Novartis, and Pfizer, Consultant of: AbbVie, Bristol-Myers Squibb, Eli Lilly, MSD, Novartis, Pfizer, Roche, UCB, Speakers bureau: AbbVie, Bristol-Myers Squibb, Eli Lilly, MSD, Novartis, Pfizer, Roche, UCB, Philip J Mease Grant/research support from: Abbott, Amgen, Biogen Idec, BMS, Celgene Corporation, Eli Lilly, Novartis, Pfizer, Sun Pharmaceutical, UCB - grant/ research support, Consultant of: Abbott, Amgen, Biogen Idec, BMS, Celgene Corporation, Eli Lilly, Novartis, Pfizer, Sun Pharmaceutical, UCB - consultant, Speakers bureau: Abbott, Amgen, Biogen Idec, BMS, Eli Lilly, Genentech, Janssen, Pfizer, UCB - speakers bureau, Filip van den Bosch Consultant of: AbbVie, Celgene Corporation, Eli Lilly, Galapagos, Janssen, Novartis, Pfizer, and UCB, Speakers bureau: AbbVie, Celgene Corporation, Eli Lilly, Galapagos, Janssen, Novartis, Pfizer, and UCB, Juergen Braun Grant/research support from: Abbvie (Abbott), Amgen, BMS, Boehringer, Celgene, Celltrion, Centocor, Chugai, Eli Lilly and Company, Medac, MSD (Schering Plough), Mundipharma, Novartis, Pfizer (Wyeth), Roche, Sanofi- Aventis, and UCB Pharma, Consultant of: Abbvie (Abbott), Amgen, BMS, Boehringer, Celgene, Celltrion, Centocor, Chugai, EBEWE Pharma, Eli Lilly and Company, Medac, MSD (Schering-Plough), Mundipharma, Novartis, Pfizer (Wyeth), Roche, Sanofi-Aventis, and UCB Pharma, Speakers bureau: Abbvie (Abbott), Amgen, BMS, Boehringer, Celgene, Celltrion, Centocor, Chugai, EBEWE Pharma, Eli Lilly and Company, Medac, MSD (Schering-Plough), Mundipharma, Novartis, Pfizer (Wyeth), Roche, Sanofi-Aventis, and UCB Pharma, Alice Gottlieb Grant/ research support from: Boehringer Ingelheim, Incyte, Janssen, Novartis, UCB, Xbiotech, Consultant of: AbbVie, Allergan, Avotres Therapeutics, Beiersdorf, Boehringer Ingelheim, BMS, Celgene, Dermira, Incyte, Eli Lilly, Janssen, LEO Pharma, Novartis, Reddy Labs, Sun Pharmaceutical Industries, UCB, Valeant, Xbiotech, Laura C Coates: None declared, Vinod Chandran Grant/ research support from: Abbvie, Celgene, Consultant of: Abbvie, Amgen, Bristol-Myers Squibb, Celgene, Eli Lily, Janssen, Novartis, Pfizer, UCB, Employee of: Spouse employed by Eli Lily, Philip Helliwell: None declared, Deepak Jadon: None declared, Joachim Sieper Consultant of: AbbVie, Boehringer
Ingelheim, Eli Lilly and Company, Janssen, Merck, Novartis, Pfizer, Roche, and UCB Pharma, Speakers bureau: AbbVie, Boehringer Ingelheim, Eli Lilly and Company, Janssen, Merck, Novartis, Pfizer, Roche, and UCB Pharma Désirée van der Heijde Consultant of: AbbVie, Amgen, Astellas, AstraZeneca, BMS, Boehringer Ingelheim, Celgene, Cyxone, Daiichi, Eisai, Eli-Lilly, Galapagos, Gilead Sciences, Inc., Glaxo-Smith-Kline, Janssen, Merck, Novartis, Pfizer, Regeneron, Roche, Sanofi, Takeda, UCB Pharma; Director of Imaging Rheumatology BV, Dafna D Gladman Grant/research support from: AbbVie, Amgen Inc., BMS, Celgene Corporation, Janssen, Novartis, Pfizer, UCB grant/research support, Consultant of: AbbVie, Amgen Inc., BMS, Celgene Corporation, Janssen, Novartis, Pfizer, UCB - consultant DOI: 10.1136/annrheumdis-2020-eular.2719

\section{$\mathrm{AB} 0825$}

TIME-COURSE CHANGE IN AXIAL MOBILITY IN PSORIATIC ARTHRITIS PATIENTS UNDER BDMARD

M. Rato ${ }^{1}$, F. Pinheiro ${ }^{1}$, S. Garcia ${ }^{1}$, B. M. Fernandes ${ }^{1}$, S. Ganhão ${ }^{1}$, R. Gaio ${ }^{2}$, M. Bernardes ${ }^{1}$, A. Bernardo ${ }^{1}$, L. Costa ${ }^{1}{ }^{1}$ Centro Hospitalar Universitário São João, Rheumatology, Porto, Portugal; ${ }^{2}$ Faculdade de Ciências da Universidade do Porto \& Centro de Matemática da Universidade do Porto, Mathematics, Porto, Portugal

Background: Spinal mobility is assessed frequently in patients with psoriatic arthritis (PsA) using Bath Ankylosing Spondylitis Metrology Index (BASMI) to provide baseline measurement, monitor changes over time and to assess the impact of clinical interventions. BASMI comprises 4 measures of spinal mobility (cervical rotation, tragus-to-wall distance, modified Schober's test and lumbar lateral flexion) and one hip mobility measurement (intermalleolar distance).

Objectives: The aim of this study is to investigate the time-course change of BASMI in PsA patients after 6 months of Biologic Disease-modifying Antirheumatic Drug (bDMARD) therapy. The authors also pretend to evaluated, at baseline and after 6 months of treatment, the association between BASMI, disease activity scores and physical function.

Methods: An observational retrospective study was performed in patients with PsA under bDMARD followed in the Rheumatology department of a tertiary university hospital. Were included patients treated with only one bDMARD. Demographic and clinical data were collected from the Rheumatic Diseases Portuguese Register. For spinal mobility calculation BASMI was used. Disease activity was evaluated with Ankylosing Spondylitis Disease Activity Score (ASDAS) and Bath Ankylosing Spondylitis Activity Index (BASDAI). Physical function was assessed with Bath Functional Index (BASFI). The variation of BASMI, ASDAS, BASDAI and BASFI was calculated as the difference between values registered at 6 months and at baseline and presented as $\Delta$. Correlations between $\triangle \mathrm{BASMI}, \triangle \mathrm{ASDAS}$ and $\triangle \mathrm{BASFI}$ was calculated using Pearson test.

Results: A total of 55 patients were included. Thirty patients were males $(54.5 \%)$. The mean age at diagnosis was $44.6 \pm 12.6$ years and the median disease duration at start of bDMARD was 5.4 years (min: 0.30 ; max: 25.5). In total, $19(34.5 \%)$ patients had predominant axial involvement, $36(65.5 \%)$ peripheric and $36(65.5 \%)$ enthesopathic. Almost all patients fulfilled the CASPAR criteria for PsA $(n=50,90.9 \%)$. According to ASDAS criteria, at the baseline 20 patients $(36.4 \%)$ had high disease activity and $34(61,8 \%)$ very high. The most used bDMARD was etanercept $(n=21,38,3 \%)$ followed by golimumab $(n=19,34.5 \%)$ and adalimumab $(n=8,14.5 \%)$. Three patients were treated with infliximab, two with certolizumab and other two with secukinumab. Forty-one patients $(75.9 \%)$ were concomitantly treated with conventional synthetic DMARDs. Axial PsA patients had more limitations in spinal mobility (BASMI mean $4.5 \pm 1.5$ ) and more functional limitation (BASFI mean 6.8 \pm 1.9 ) than patients with predominant peripheric involvement (BASMI mean 3.3 $\pm 1.2, p=0.004$; BASFI mean $5.4 \pm 3, p=0,0048$ ). Statistically significant differences in ASDAS and BASDAI in these two groups were not observed $(p=0.332$ and $p=0.605$, respectively). For all patients, BASMI did not vary significantly $(p=0.691)$ at baseline (mean $3.7 \pm 1.4)$ and after 6 months (mean $3.8 \pm 1.3$ ) of treatment. Although the $\triangle B A S M I$ for etanercept was negative (mean $-0.12 \pm 0.9$ ) and for golimumab positive $(0.14 \pm 0.8$ ), it was not statistically significant. At baseline there is a significant positive association between BASMI and ASDAS ( $r=0.435, p=0.001)$, BASMI and BASDAI $(r=0.567, p<0.001)$ and BASMI and BASFI $(r=0.510, p<0.001)$. How ever, there was not a statistically significant association between $\triangle B A S M I$ and: $\triangle$ ASDAS, $\triangle$ BASDAI and $\triangle$ BASFI $(r=0.158 ; p=0.269, r=0.019 ; p=0.096$ and $r=0.121 ; p=0.397$, respectively).

Conclusion: In PsA patients treated with bDMARDs, at least in short-term follow-up, BASMI does not improve with time. Changes in BASMI did not correlate with changes in activity disease and in functional outcome. Studies with longer follow-up and with more patients are needed to better evaluate these associations. 